\title{
El médico visto desde la sociedad por una presidenta de Colegio de Médicos
}

\author{
Juliana Fariña González \\ Ilustre Colegio de Médicos de Madrid
}

Trataré de exponer, desde la perspectiva de una presidenta de colegio, cómo creo que la sociedad nos ve a los médicos.

Para acercarme a ello, he buscado los argumentos en hechos existentes en la sociedad e incluso he hecho la pregunta directa a algunos de sus miembros, concretamente en el programa de televisión del Colegio de Médicos de Madrid, "El Semanal de la Medicina", que se emite los sábados por Canal 7.

¿Qué he obtenido?: Que los médicos seguimos teniendo buena reputación y que existe una sinergia entre el sentir del médico y del paciente respecto a la necesidad de que al médico se le ayude concediéndole más tiempo para poder estudiar con sosiego a los enfermos.

La sociedad percibe los problemas de sus médicos y no está de acuerdo con que no se les provea de lo necesario, pues como ha dicho una de las entrevistadas, "la salud es lo primero". Las contestaciones de las personas preguntadas dejan muy claro que el médico es una figura fundamental, querida, respetada, que se comporta de forma cercana a la vida social y que se preocupa por los pacientes.

Esta primera impresión positiva se ve reforzada al comprobar que muchos jóvenes, notablemente capacitados, desean con avidez que la profesión a la que dedicar su vida sea la Medicina. De hecho, la calificación exigida en los exámenes de selectividad para entrar en las Facultades de Medicina es, en nuestro país, una de las más elevadas.

Estos futuros médicos no son ajenos a los problemas de nuestra profesión, como la mala remuneración. Todas las comunidades autónomas proporcionan honorarios realmente vejatorios, comparados con los que reciben compañeros de países de nuestro entorno como Portugal, Francia, Reino Unido, Alemania o Suecia, por poner sólo unos ejemplos. Nuestros colegas extranjeros ganan sueldos triplicados que triplican, o más, a los que se pagan en España.

Estos universitarios, embriones de médicos, saben que se nos pide un grado de excelencia y de estudio máximo durante toda la vida, y lo comprenden porque en nuestro trabajo se dirime la vida. También con conscientes de que la sociedad no consiente al médico el mínimo error, aunque esto ocurre en todas las profesiones y trabajos y con resultados desgraciadamente también graves.

Recordemos, por ejemplo, los llamados puntos negros de las carreteras, que se corresponden a tramos dónde se producen más muertes por accidentes de tráfico. Sin embargo, en ellos, ni se hace un estudio de qué personas y factores han intervenido en su construcción, y -lo que es más insólito aún-, la Administración no los corrige ni indemniza en caso de accidente.

Los estudiantes también advierten que los medios de comunicación, cuando hablan de los médicos, a veces publican sus nombres, olvidando la presunción de inocencia y el derecho a su imagen, que como cualquier ciudadano tienen hasta que no haya sentencia judicial firme. Aunque desde aquí reconozco, y me es grato decirlo, que ahora sucede con menos frecuencia que hace unos años.

También podemos considerar que el número de Facultades de Medicina es una señal del deseo y aprecio que tiene la sociedad por los médicos. Así, en la actualidad, contamos con más de 20 y en algunas ciudades, como Barcelona y Madrid, con más de dos. Esto señala la necesidad de la Medicina en la sociedad frente a otras ramas del saber que, al igual que ella, han dado pasos de gigante en el siglo XX, con- 
siguiendo cotas extraordinarias de bienestar y autonomía para las personas.

En la sociedad, este deseo de salud y de médicos se evidencia también en los medios de comunicación: televisión, radio, prensa escrita e Internet. Hace ya años que Ramón Sánchez-Ocaña alcanzó una gran popularidad en la pequeña pantalla con sus programas divulgativos de salud -enfocados a enseñar a la población comportamientos saludables-, mientras que la serie del Dr. Ganon nos adentraba en un mundo de ficción sanitaria. Hoy, el protagonismo es aún mayor. De hecho, en cuatro teleseries, atractivos artistas nacionales y extranjeros encarnan a los doctores Vilches, House, Carter y Ross, personajes ya casi míticos.

Por su parte, todos los periódicos de tirada nacional cuentan con periodistas especializados en el área sanitaria, como las prestigiosas firmas de José María Fernández Rua y Nuria Ramírez en ABC, José Luis de la Serna en El Mundo, Oriol Güell y Maika García en El País, o Rosa Serrano en La Razón. Las noticias sanitarias ocupan gran parte de la sección de Sociedad, lo que indica claramente que el médico es un personaje clave en ella.

Sus artículos son un todo un referente en el tema y sus magnificas plumas consiguen explicar con sencillez los hallazgos científicos y divulgar consejos y pautas de vida saludables a la población. Asimismo, estos comunicadores han conseguido que se conozcan nuestros problemas, aciertos y defectos. Todo este interés se puede palpar, por ejemplo, en el Master de Periodismo Sanitario que se otorga en la Universidad Complutense y que cuenta con numerosos alumnos periodistas.

También quiero analizar de forma muy breve el éxito del medico en el tejido social. Probablemente, en la noche de los tiempos, una persona se sintió mal o disminuida en sus capacidades y se lo contó a otros; alguien la escuchó e intentó ayudarla. Éste se convirtió en el primer acto médico, en la primera relación médico-paciente, núcleo esencial de la Medicina. La persona se encontró al menos confortada al ver que sus quejas eran atendidas y en su corazón nació el agradecimiento a ese primer médico de la Historia.

Pues sí, en efecto, los médicos tenemos suerte, porque aunque todas las profesiones son necesarias y tienen su justo reconocimiento en la sociedad, no hay duda que la persona más importante del mundo para cada uno de nosotros somos nosotros mismos y, por tanto, el mayor agradecimiento va dirigido a aquél o aquéllos que hacen posible que lo tengamos en óptimas condiciones.
Este prestigio social desgraciadamente también se basa en la existencia de la salud rota. La enfermedad existe desde siempre y en general es la principal causa de fallecimiento, seguida de los accidentes y las agresiones. A su vez, la muerte es temida por una gran mayoría y nuestra relación con la posibilidad de alejarla hace que, en algunos casos, la sociedad nos vea como depositarios de poder y como portadores de esperanza.

Todo el mundo sabe que con las personas enfermas es muy difícil convivir, y es precisamente el médico quien se acerca a ellas, le mira a los ojos, le habla, le toca y trata de ayudarle, aunque a veces se equivoque. Esta relación no es en absoluto baladí ni para el paciente ni para el médico.

En innumerables ocasiones, los médicos hacemos cosas a favor de nuestros pacientes, no comprendidas por las familias ni por la sociedad, y a veces hasta en contra de nosotros mismos. Esta relación tan directa con la acción probablemente hace al médico atractivo a la sociedad. Son tan decididos los médicos a actuar que a los estudiantes a los que doy clases les comento a menudo que cuando entre varios niños jugando uno se cae y se hace daño, si hay alguno que se agache, le toca, trata de moverlo o limpiarle la herida, cualquier cosa, aunque no le beneficie, ese niño es un posible médico, si otro de los niños se acerca a la escena en silencio mirando sin hablar probablemente es un periodista o escritor y si mira hacia varios lados tiene madera de político.

Otra característica que también hace a los médicos ser queridos es la incertidumbre que tiene nuestra ciencia por tener algo de arte, que tiene que ser por tanto reconocida por lo demás y de a ahí lo necesario que es para conseguir la mejor medicina para el paciente que sea este quien tome la decisión de elegir al médico al que quiere ir. La libre elección de médico y un tiempo de comunicación adecuado son fundamentales para disminuir las denuncias por supuesta mala practica médica.

La relación de los médicos con los pacientes es tan estrecha con estos y sus problemas que impregna nuestras vidas y puede que se nos refleje en el rostro. Curiosamente, sin haber llegado a pronunciar una sola palabra, a veces personas que nos acaban de conocer en el transcurso de un viaje o de una cena de amigos adivinan enseguida y preguntan afirmando sobre nuestra profesión.

¿Será que llegamos a tener un orden tan diferente de valores que se manifiesta en nuestra espontánea independencia ante los convencionalismos sociales o en el gran disfrute que exhibimos ante cualquier 
hecho grande o pequeño, siempre que sea bueno y no haga daño a nadie?

Sí, la independencia es uno de los factores que ha hecho y hace tan atractivos a los médicos. Siempre lo han sido porque su profesión es casi transportable en un maletín, porque no tiene fronteras, porque los valores a los que se comprometen públicamente a cumplir son básicamente los mismos del juramento hipocrático. Estos signos de independencia se ven frecuentemente en películas como "El puente sobre el río Kway" o "El árbol del ahorcado".

Además, esa independencia ha sido y es respetuosa con todas las políticas, religiones y poderes. Echemos la vista atrás: Si en Roma eran famosos los médicos griegos, en España lo fueron los médicos judíos. Una de las más bellas oraciones para los galenos la escribió precisamente Maimónides, ese médico judío de Córdoba expulsado por los árabes.

La profesión médica, en correspondencia con los cambios científicos, tecnológicos y sociales, también está evolucionando. Sin embargo, nuestra misión fundamental de saber diagnosticar la enfermedad, prescribir y administrar el tratamiento correcto, y tratar de prevenirla, sigue siendo el núcleo más técnico que mantenemos, junto con los atributos indispensables de humanidad y empatía con el enfermo, de tal manera que nuestro fin de curar -y si no es posible, sólo de aliviar y siempre de consolar- se mantiene absolutamente firme. La tradicional relación médico-paciente sigue siendo completamente necesaria: ese acercarse a los enfermos uno a uno, tocarles, palparles, escudriñar sus ojos, verles su boca por dentro, meditar sus palabras...

Desde aquí tengo que denunciar que hoy la Medicina es tan deseada por la sociedad que a veces se ha convertido en un negocio. En algunos casos, alrededor de esa relación médico-paciente se está secuestrando la labor individual del médico y se están montando una serie de servicios y condicionantes accesorios -ni siquiera estrictamente sanitarios- que están encareciendo hasta límites insospechados el cuidado de la salud.

Estoy convencida que esa medicina industrial que algunos pretenden no tiene mucho futuro y que su afán por conseguir clientes en vez de pacientes, ganar dinero y obtener recompensas sociales, se opone a la verdadera naturaleza del acto médico. La relación íntima médico-paciente es el verdadero centro de la Medicina, e incluso está demostrado que posee un componente terapéutico.

Desde aquí pido a los administradores privados y públicos que, al gestionar un centro sanitario o una unidad médica, tengan siempre presente una premisa a cumplir en toda partida de gasto: Que, en todos los casos, una parte del dinero que se vaya a gastar se dedique a mejorar la realización del acto médico a través de esa relación médico-paciente.

De nada valen los proyectos que no tengan repercusión a este nivel; de nada sirve desviar presupuesto exigiendo más calidad y ahorro a los médicos. Así nos puede llegar a pasar lo que a Groucho Marx en "Los hermanos Marx en el Oeste", cuando para alimentar la caldera quemaba madera y más madera necesaria para el funcionamiento del tren.

Un índice externo que se puede chequear para descubrir cuando la relación médico-paciente esta debilitada, aunque haya un gran despliegue de medios, es el aumento del intrusismo con las llamadas medicinas alternativas milagrosas... y sobre todo peligrosas para la población.

Por último, no quiero obviar que, a veces, la figura del médico ha sido denostada y olvidada, y, desde luego, que no siempre ha sido adecuada valoración, sobre todo entre los sanos. Cuando se es joven o se tiene salud, poca gente recuerda o valora la existencia de la Medicina y de sus profesionales. Es algo que ha sucedido a lo largo de la historia, pero ahora, con el conocimiento claro de la enfermedad, es prácticamente imposible que alguien no sienta el deseo de tener una vida saludable o, mejor aún, más y más saludable.

¿Conclusión?: La presencia de un médico en un acto social o en una reunión es hoy más que nunca foco de atención.

Pues bien, ¿cómo ve actualmente la sociedad al médico? Pienso que como a una persona que suscita interés y con un alto grado de aceptación, tal como lo confirman las estadísticas. En todas ellas la profesión mejor valorada es la de médico y así la ponen en primer lugar más del $80 \%$ de los preguntados. 